\title{
Orta Öğretim Öğrencilerinin Serbest Zamanda Yaptıkları Spor Aktivitesinin Kişilik Yapıları Üzerine Etkisi
}

\author{
Osman Tolga TOGO*
}

\begin{abstract}
Öz
Bu araştırmanın amac1, Muğla ilindeki "12 Dev Adam Basketbol Okulları” projesine katılan ve yaşları 11-14 yaş arasında değișen 30 erkek öğrencinin serbest zamanda yaptıkları basketbol aktivitesinin kişilik yapılarına etkisini araştırmaktır. Bu amaçla,11-14 yaş(STD. 12.62)grubu gelişim çağındaki çocuklara 8 hafta boyunca devam eden çalışma öncesi ve çalışma sonrası kişilik (benlik) tasarımı anketi uygulanmıştır. Alınan anket verilerin analizi için SPSS programında Paired Samples T-test (Bağımlı örneklem T-testi) uygulanmıştır. Öğrencilere uygulanan anket sonucunda, basketbol aktivitesinden önceki verilerin ortalaması x; 72,86 ss;17,50, basketbol aktivitesinden sonraki verilerin ortalaması x; 91,46 ss;9,41 olarak tespit edilmiştir. Araştırma sonuçlarına göre,8 haftalık çalışma öncesi ve çalışma sonrası verilerde bu yaş grubu gelişim çağındaki çocuklara uygulanan kişilik (benlik) tasarımı ile uygulanan anket sonucuna göre $\mathrm{P}<0,05$ düzeyinde anlamlı farklılığa rastlanmıştır.
\end{abstract}

Anahtar kelimeler: Çocuklar, basketbol, serbest zaman, kişilik.

\section{Secondary Education Students Effects of Personality Structure in Recreational Sports Activity}

\begin{abstract}
The aim of this research is to investigate the effect of recreational basketball activity on personality of 30 male students (aged between 11-14 years) who participated "12 Dev Adam Basketball School” project in Muğla. Fort this purpose, personality (ego) survey was implemented to the teenage participants (Standart Deviation,12,62) at the beginning of the Project and after 8 weeks when the Project ended. Paired Samples T test in SPSS was conducted for analysis of survey data. The average data for the pre and post Project were 72,86 ss;17,50 and 91,46 ss;9,41, respectively. Results showed that there was a significant difference $(\mathrm{P}<0.05)$ between pre and post Project for the personality of teenage participants in this age group.
\end{abstract}

Keywords: Teenagers, basketball, recrational activity, personality.

\footnotetext{
* Arş. Gör., Marmara Üniversitesi Spor Bilimleri Fakültesi, tolgatogo@gmail.com
} 


\section{GíRiş}

Özellikle ülkemiz gibi gelişmekte olan ülkelerde spor önemli bir dinamiği oluşturur. Spor büyük bir toplumsal dinamiktir. Çünkü, giderek daha çok kişi tarafından doğrudan ya da dolaylı olarak ilgi görmeye başlamış daha organize hale gelmiş ve uluslararası bir saygınlık prestij gösterisi konumunu alarak ulusları sevince ya da yasa sürüklemeye başlamıştır.

Sporun insan sağlığı ve insan gelişimi için ne oranda önemli olduğunun bilinci ülkemizde anlaşlamamıştır. Her şeyin ötesinde bir çocuğun fiziksel ve mental (zihinsel) gelişim sürecinde spor çok önemli bir etki yapmaktadır (Biçer,2008).

Spor onun sağlğ̆ına ve gelişimine koyacağı önemli katkıların dışında, onun kişiliğinin oluşumunda paylaşma, ekip çalışması gibi günümüz dünyasında çok önemli olan kavramlarla tanışmasına ve onları benimsemesine yol açar.

Spor, günümüzde toplumsal, ekonomik ve kültürel pek çok olgu ile birlikte anılmaktadır. Bireyin ergenlik öncesi ve sonrası düzenli olarak katıldığı spor faaliyetleri sağlıklı bir fiziki yapının gelişmesine yardımcı olurken, diğer taraftan ruhsal gelişmeye de katkıda bulunur. Gelecekte toplumda sorumluluk alacak yetişkinlerin iyi alışkanlıklar edinmesinde, bireyler arası ilişkilerin kurulması ve devam ettirilmesinde çocukluktan başlayan spor yaşamı büyük önem kazanmaktadır(Kasatura,2008).

Basketbol, son yıllarda diğer dünya ülkelerinde olduğu gibi ülkemizde de popüler spor dallarından biri olmuştur. Teknolojik gelişme ile birlikte 100 yaşını tamamlayan bu oyunda teknik, taktik ve diğer bilgiler evrensel boyuta ulaşmıştır. Bu bilgilerin gelişimi günümüzde de devam etmektedir.

Günümüz dünyasında, çağdaş yeni gelişmelere anında uyum sağlamaya çalıșan, kendisi yeni gelişmelere imza atan, bunları gerçekleştirirken "iki ayağı bir pabuca giren insan için zaman nedir?

Zaman bir fiilin, bir iș veya oluşun geçtiği, geçeceği veya geçmekte olduğu süre vakit; meydana gelen olayları sıralamaya yarayan başsız ve sonsuz mücerret, soyut bir kavramdır.

T.D.K ise zamanı; olayların ardışılarını görerek aklımızda yarattığımız ve olayların bundan sonra da içinde olup gideceklerini düşündüğ̈ümüz, başı ve sonu olmayan soyut kavram olarak açıklamaktadır.

İnsan yaşamının yerine göre uzun ya da kısa süreli, yinelenmesi olanaksız, başlangıcı ve sonucu belli, saatle ölçülebilen bir bölümüdür (Biçer,2008).
Zaman;
a) Var olmakla ilgili zaman
b) Geçimle ilgili zaman
c) Serbest zaman

Psikoloji bilimi içinde önemli bir yere sahip ve pek çok kuram içinde yer alan önemli bir kavram "benlik"(kendilik)ve bu sistemi inceleyen "benlik psikolojisidir. 
Benlikbireyinkendisihakkındasahipolduğuduyumlarıntümüolaraktanımlanmıştır(Dusek,1987).

Daha geniş bir ifadeyle bireyin davranış biçimini tespit eden, kavramlarının değerlerinin, amaçlarının ve ideallerinin dinamik organizasyonu olarak tanımlanabilir. Bu duyumlar, bireyin sosyal ortamda diğer insanlarla etkileşimi sonucu gelişir ve güçlenir.

Yani özne olarak ben, saf egonun ya da özne olarak benliğin bir görüntüsüdür ve bu yapılanım içinde bireyin yaşantıları, duyumları ve planları yer almaktadır. Nesne olarak "ben "ise, bilinçliliğin, bilinenin, deneyimin bir nesnesi olarak kabul edilmiştir. Nesne olan ben, yaşantılardan ve deneyimlerden etkilenen olmasına karşılık, özne olarak ben, aktif ve etkileyen konumundadir(Koç,2004)

James," fiziksel ben"(beden, giyim, aile, mülk),"sosyal ben"(ün, tanınma, önemli kişileri tanıma vb.)ve "manevi ben"(düşünce, duygu ve davranımların etkin olarak farkında olma) olarak bütünleştirdiği "bilinen benlik" kavramından söz etmiştir (Dusek,1987).

Benlik, bireyi oluşturan tüm özelliklerin karmaşık bir örüntüsü iken; benlik kavramı(self concept), kişinin kendisi hakkındaki görüşünü ifade etmektedir. Benlik kavramı, bir bireyin özellik ve değerlerinin bütününün oluşturduğu, kişilik yapısının çekirdeği olarak tanımlanmıştır.

\section{YÖNTEM}

\section{Araştırmanın Amacı}

Haftada 3 gün 1,5 saat uygulanan basketbol aktivitesinin,12 Dev Adam basketbol okullarına gelen çocukların kişilik (benlik) yapılarına etkisini ortaya koymak amacıyla yapılmıştır.

\section{Araştırmanın Evren ve Örneklemi}

$\mathrm{Bu}$ araştırmanın evrenini Muğla ilinde okuyan ve yaşları 11-14arasında değişen erkek öğrenciler oluşturmaktadır. Araştırmanın örneklemini ise, Muğla ilinde açılan 12 Dev Adam Basketbol Okulları’nda basketbol antrenmanlarına katılan yaşları 11-14 arasında değişen 30 erkek öğrenci oluşturmaktadır.

\section{Veri Bilgi Toplama Yöntem ve Aracı}

Araştırmada,2005-2006 yılı Muğla 12 Dev Adam basketbol okulunda eğitim almakta olan bu yaş grubu erkek öğrenciler denek grubunu oluşturmuştur. Bu çalışma literatür tarama yöntemi ile anket tekniklerinden faydalanarak yapılmıştır. Konuyla ilgili bilgiler çeşitli kaynaklardan toplanmış ve araştırmada Araştırmaya katılan denekler üzerinde, Baymur'un (1968) benlik tasarımı envanteri (anket testi) uygulanmıştır. Bu maddelerin her biri bir bireyin kendisine ilişkin bir duygusunu, düşüncesini ya da değerlendirilmesini yansitabilecek bir ifadeden oluşmaktadır. Envanter deneklere bir cevap kağıdı ile birlikte verilmektedir. Cevap kağıdında her ifade için "Tam benim gibi”, "Biraz benim gibi”, "Kararsızım”, "Hayır” ve "Asla” şeklinde beş 
seçenek bulunmakta ve denekler her ifadenin kendilerini yansıtma derecesini bu seçeneklerden birisini işaretleyerek belirtmektedirler.

Envanterin puanlanması cevap seçeneklerine +2 ile -2 arasında değişen değerler verilmek suretiyle yapılmaktadır. Envanterlerde yer alan 65 ifadeden 32 si bireyin kendisine ilişkin olumlu bir duygu, düşünceyi ya da değerlendirmeyi, 33’ü ise olumsuz bir duygu, düşünce ya da değerlendirmeyi yansıtacak şeklinde oluşturulmuştur. Olumlu bir ifadeye verebilecek "tam benim gibi" cevabı ise, olumsuz bir benlik tasarımı, "asla" cevabı ise, olumsuz bir benlik tasarımı anlamına gelmektedir. Buna karşı, olumsuz bir ifadeye verilen "asla" yanıtı olumlu bir benlik tasarımını, "tam benim gibi” yanıtı ise, olumlu bir benlik tasarımını yansıtmaktadır. Böylece, her cevap seçeneğine verilen değer, seçenekle ilgili ifadenin olumlu ya da olumsuz oluşuna göre değişmektedir.

Olumlu ifadelerde "Tam benim gibi" seçeneğine +2 , "Biraz benim gibi" seçeneğine +1 , "Kararsızım" seçeneğine 0, "Hayır" seçeneğine -1, "Asla” seçeneğine -2 puan verilmektedir. Olumsuz ifadelerde ise +2 puan "asla" seçeneğine verilmekte, diğer seçeneklere verilen puanlar sırasıyla $+1,0,-1$ ve -2 olmaktadır. Her deneğin envanteri bu şekilde puanladıktan sonra aldığ $1+$ ve - puanlar toplanarak, kendisi için bir "benlik tasarımı" puan elde edilmektedir. Envanterden alınabilecek en yüksek puan +130 , en düşük puan ise -130 'dur. Yüksek puan olumlu, düşük puan ise olumsuz bir benlik tasarımına işaret etmektedir.

\section{Veri Bilgilerinin Analizi ve Değerlendirilmesi}

Araştırmada,"12 Dev Adam Basketbol Okulları" projesi çerçevesinde Muğla ilinde yapılan basketbol çalışmalarına katılan 30 erkek öğrenci denek seçilmiştir. Denekler bu çalışmaya gönüllü olarak katılmışlar ve sağlık yönünden herhangi bir problemleri olmadığ 1 tespit edilmiştir. Araştırmada ankete verilen cevaplar tek tek incelendikten sonra veriler elde edilmiş olup SPSS paket programında değerlendirilmeye alınmıştır.

\section{Deney Grubuna Uygulanan Antrenman Programı}

"12 Dev Adam Basketbol Okulları" antrenmanlarına katılan deneklere, 8 hafta boyunca yapılan antrenmanlar kapsaminda genel olarak; basketbol oyununun temel teknikleri, denge yeteneği, oyun bilgisi ve eğitsel oyunlar oynatılmış ve gösterilmiştir.

Yapılan çalışmaları aşağıda belirtilen sıra halinde toplamak mümkündür:

\section{Top Sürme Çalışması;}

- $\quad$ Durarak geri iki el ile yüksek top sürme çalışması

- Durarak alçak top sürme çalışması 
- Çeşitli pozisyonlarda top sürme çalışması(oturarak, yatarak, dönerek, iki top ile çalışmalar)

- Yürüyerek, daha sonra koşarak el ile yüksek ve alçak top sürme çalışması

- Top sürme yaparken yön değiştirme çalışması

\section{Turnike Çalışması;}

- Sağ ve sol turnikenin adımlamaları

- Yürüyerek elden alınan pas ile turnike

- $\quad$ Top sürme sonrası sağ ve sol el turnike

- Uzaktan alınan pas sonrası turnike

- Her iki taraftan ters turnike

\section{Şut Tekniğinin Öğretilmesi;}

- $\quad$ Şut tekniğinde; gövdenin, bacakların, kolun ve el bileğinin hareketinin öğretilmesi

- Durarak şut atma tekniği

- Siçrayarak şut atma tekniği

\section{Daha önce öğrenilen; pas, top sürme, turnike ve şut tekniklerinin koordineli olarak uygulandı̆̆ı antrenman drilleri;}

- Top sürme sonrası pas-şut-turnike

- $\quad$ Pas sonrası şut-top sürme-turnike-pas

- $\quad$ Öğrenilen basketbol tekniklerinin sergilendiği çeşitli driller ve müsabakalar

\section{Aldatma Hareketleri;}

- $\quad$ Top sürme aldatmaları

- Şut aldatmaları

- Pas aldatmaları

- Koşu aldatmaları 


\section{Perdeleme( Screen ) Çalışması;}

- Düz perdeleme

- Ters perdeleme

- Perdeleme sonrası devrilme

\section{Her Hafta Antrenman Sonrası Yapılan Uygulamalar}

- Oyun kuralları bilgisi

- Eğitsel oyunlar

- Öğrenilen basketbol tekniklerinin sergilendiği çeşitli müsabakalar

Yukarıdaki programda görüldüğü gibi; basketbol temel tekniklerinin ağırlıklı olarak verildiği çalışmalarda antrenmanlara katılanların sıkılmadan, eğlenerek basketbol hakkında bilgi edinmeleri ve beceri kazanmaları amaçlanmıştır.

\section{BULGULAR}

Tablo I. Deney grubuna yapılan anketin T-testi sonuçları

\begin{tabular}{lcccc}
\hline Değişken & $\bar{X}$ & $\mathbf{N}$ & Ss & p \\
\hline Önce & 72,8667 & 30 & 17,5022 & 0.000 \\
Sonra & 91,4667 & 30 & 9,4129 & \\
\hline
\end{tabular}

11-14 yaş grubu 30 çocuğun deney grubu olarak katıldıkları anketin T-testi sonuçları yukarıdaki tabloda görülmektedir. Buna göre deney grubu üzerinde yapılan ölçümler sonunda, basketbol aktivitesinden önceki verilerin ortalaması x; 72,86,ss; 17,50 basketbol aktivitesinden sonraki verilerin ortalaması x; 91,46ss; 9,41 olarak tespit edilmiştir. Deney grubuna yapılan ölçümler sonunda $\mathrm{p}<0,05$ düzeyinde anlamlı farklılığa rastlanmıştır. 
Tablo 2. Deney grubunu oluşturan bireylerin ilk test ve son test arasındaki artışın fark grafiği

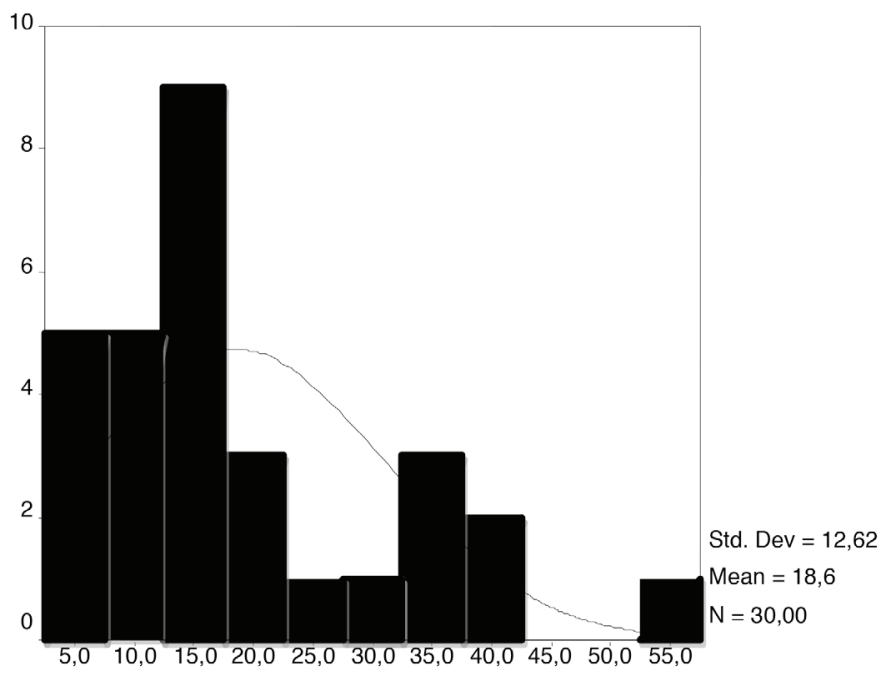

FARK

Basketbol antrenmanlarına katılan bireylerin ilk test ve son test anket ölçümlerindeki fark yukarıdaki tabloda görülmektedir. İlk test ve son test arasındaki farklar 5 ile 55 sayıları arasında değişkenlik göstermektedir. Genel aritmetik ortalama olarak da 18,6 oranı elde edilmiştir.

Tablo 3. Egzersiz öncesi ve egzersiz sonrası dağılımı grafiği

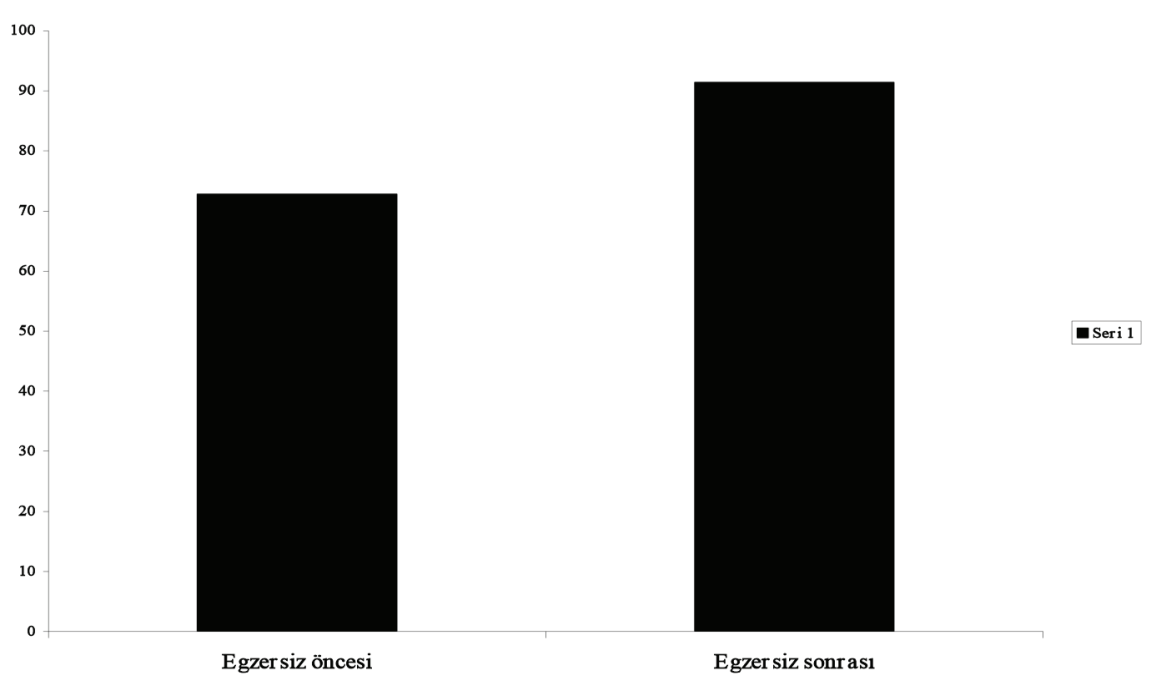

Egzersiz öncesi ve sonrası bulunan aritmetik ortalamalar yukarıdaki tabloda gösterilmiştir. Egzersiz öncesi ortalamalar x;72,8 iken, egzersiz sonrası x;91,4 olarak saptanmıştır. 


\section{TARTIŞMA}

$\mathrm{Bu}$ araştırmada, "12 Dev Adam Basketbol Okulları” projesi çerçevesinde Muğla ili'ndeki basketbol antrenmanlarına katılan ve yaşları 11-14 arasında değişen 30 erkek öğrenci üzerinde gerçekleştirilmiştir.

Basketbol çalışmalarına katılan 11-14 yaş arasındaki gelişim çağındaki erkek öğrenciler haftada 3 antrenman olmak üzere 2 ay ( 8 hafta) basketbol antrenmanı yapmışlardır.

Araştırmaya katılan denekler üzerinde, Baymur'un (1968) benlik tasarımı envanteri (anket testi) uygulanmıştır. Baymur (1968) tarafından geliştirilen Benlik Tasarımı Envanterinde 65 madde bulunmaktadır. Anketler, çalışmaya başlamadan önce ve çalışma sonrası yapılmış olup, verilerin ilk ve son anket uygulamaları karşılaştırılmış ve sonuç olarak yapılan anketlerde deneklerin ilk ölçümlere göre aşama kaydettikleri belirlenmiştir.

Slutzky ve Ark.(2009) yapmış olduğu çalışmada spor için harcanan zamanın benlik saygısı değerlerini olumlu yönde etkilediği sonucu çalışmamızla paralellik göstermektedir.

Fletcher ve Dowell (1971), tarafından atletler ve atlet olmayanlar arasındaki kişilik özellikleri farkını ölçmek üzere lise birinci sınıfta okuyan toplam 950 erkek öğrenciye Edwards Kişisel Tercih Envanteri (EPPS) uygulanmıştır. Sportif etkinlikte bulunanlar(atletler), sporcu olmayanlara göre başatlık (önde olan) ve düzen gereksinimlerine ilişkin puan ortalamalarının daha yüksek olduğu saptanmıştır.

Yaz spor okullarına katılan öğrencilerin benlik saygısı puanlarının karşılaştırıldığı bir araştırmada, yaz okullarına katılan öğrencilerin genel benlik saygısı, sosyal benlik saygısı, akademik benlik saygısı, ön test ve son test toplam puanları arasında istatistiksel olarak anlamlı fark saptanmıştır. Spor yapmanın bir guruba ait olmanın benlik saygısı üzerinde olumlu etkisini yansitan bu sonuç özellikle çocukların 78 sadece yazın değil tüm yıl boyunca pedagojik formasyona sahip antrenörlerle birlikte yıl boyunca çalışma yapmalarının yararlı olacağını ortaya koymaktadır. Branşa özgü yaz spor okulu ile tam gün süren yaz okulunu karşılaştırdığımızda tam gün süren yaz okullarının genel benlik saygısı üzerinde istatistiksel olarak anlamlı bir fark bulunmuştur (Korkmaz, 2007).

Koruç ve Bayar (2000), bu araştırmada MMPI Minnesota Çok Yönlü Kişilik Envanteri kullanılarak takım sporları ve bireysel sporlarda yer alan sporcuların kişilik özellikleri arasındaki fark araştırılmıştır. Milli takım düzeyinde 368 sporcuya uygulanmış, takım sporu yapan kadınlar 59, bireysel spor yapan kadınlar 87, spor yapmayan kadınlar 96,takım sporu yapan erkekler 68 , bireysel spor yapan erkekler 154, spor yapmayan erkekler 75 kişidir.

Takım sporları yapan kadınlar ile spor yapmayan kadınların karşılaştırılmasında takım sporları yapan kadınların daha güvenlik, enerjik, maceracı, risk almaya eğilimli, gereksiz kaygılardan uzak, kurallara uyan dengeli ve daha dışadönük, takım ve bireysel spor yapan kadınların karşılaştırılmasında takım

sporlarında yer alan kadın sporcuların daha dışa dönük, daha sosyal, daha aktif, daha girişken, daha az yaratıcı, sosyal açıdan daha uyumlu olduklarını bireysel spor yapan kadınlarınsa daha yaratıcı, daha az girişken, daha tepkisel, daha içe dönük olduklarını göstermektedir. 


\section{SONUÇ ve ÖNERILER}

Bireysel spor yapan erkeklerin, spor yapmayan erkeklere göre daha uyumlu, daha girişken, saldırgan, kendilerine yönelik meraklı, toleranslı, sorumluluklarını yerine getirmede titiz, yaratıcı olduklarını, takım sporu yapan erkeklerin daha uyumlu, girişken, toleranslı, titiz, yaratıcı olduklarını göstermektedir. Bireysel ve takım sporu yapan erkekler karşılaştırıldığında takım sporu yapan erkekler daha toleranslı, estetik, düşünebilen, daha az saldırgan bireyler olduğu şeklinde yorumlanmıştır.

Araştırma sonucu olarak,2 aylık ( 8 haftalık) çalışma öncesi ve çalışma sonrası uygulanan verilerde bu yaş grubu gelişim çağındaki çocuklara uygulanan kişilik (benlik tasarımı) anketinde bilimsel açıdan anlamlı farklılığa rastlanmıştır. $(\mathrm{P}<0,05)$ 


\section{KAYNAKLAR}

Akandere M, Tekin M, Arslan F.(2006).Beden eğitimi ve spor yüksekokulunda ve üniversitenin diğer bölümlerinde öğrenim gören diğer öğrencilerin çsşitli değișkenlere göre atılganlık düzeylerinin incelenmesi. 9. Uluslar Arası Spor Bilimleri Kongresi, s. 1000, Muğla.

Baștuğ, G. (2008). Bayan Sporcuların Bedenlerini Algılama Düzeyleri Ve Cinsiyet Rolleri Üzerine Bir Araştırma, (Yayınlanmamış Doktora Tezi) Gazi Üniversitesi, Eğitim Bilimleri Enstitüsü, Beden Eğitimi Ve Spor Öğretmenliği Anabilim Dalı, Ankara.

Biçer, T. (2008).Doruk Performans. Beyaz Yayınları. İstanbul.

Çeçen, R.A.(2008).Üniversite Öğrencilerinde Yasam Doyumunu Yordama da Bireysel Bütünlük (Tutarlılık) Duygusu, Aile Bütünlük Duygusu ve Benlik Saygısı. Eğitimde Kuram ve Uygulama, 4(1): 19-3.

Dusek,J,B.(1987). Adolescent Development andbehavior,Prentice-Hallİnternational,Usa,s:370

Güler D, Aydos L, Koç H. (2005). Devlet ilköğretim 6, 7 ve 8. sinıf öğrencilerinin eğitim düzeylerinin ve sportif faaliyetlere katılımlarının atılganlıklarına etkisi. Beden Eğitimi ve Spor Eğitiminin Performansının Felsefi Temelleri Sempozyumu, Manisa.

Kasatura,İ. (2008).Kişilik ve Özgüven, Evrim Yayınevi, İstanbul.

Kiper İ.(1984).Saldırganlık Türlerinin Çeşitli Ekonomik, Sosyal ve Akademik Değişkenlerle İlişkisi. Yayınlanmamış Yüksek Lisans Tezi, Ankara Üniversitesi, Ankara.

Koç, M. (2004). “Gelişim Psikolojisi Açısından Ergenlik Dönemi ve Genel Özellikleri.” Marmara Üniversitesi SBE Dergisi. Yil 2 Sayı 17. ss.225-230.

Korkmaz, H.N.(2007).Yaz Spor Okulları İle Çocukların Benlik Saygısı Arasındaki İlişki, Uludağ Üniversitesi Eğitim Fakültesi Dergisi.

Menteș A. (2007).Lise Öğrencilerinin Atılganlık Düzeyine Sporun Etkisi. Yayınlanmamış Yüksek Lisans Tezi, Gazi Üniversitesi Eğitim Bilimleri Enstitüsü Eğitim Bilimleri Anabilim Dalı, Ankara.

Tekin M, Akandere M, Arslan F.(2006).Spor yapan ve yapmayan ilköğretim okullarında öğrenim gören öğrencilerin çeşitli değişkenlere göre atılganlık düzeylerinin incelenmesi.9. Uluslar Arası Spor Bilimleri Kongresi, s. 996, Muğla.

Tiryaki Ş, Erdil G, Acar M, Emlek Y. (1991).Sporcu ve sporcu olmayan gençlerin kişilik özellikleri. Spor Hekimliği Dergisi 26: 19-23.

Yiğit, H. (2010).Ergenlerin Benlik Saygılarının Yaşam Doyumu ve Bazı Özlük Nitelikleri Açısından İncelenmesi, (Yayınlanmış Yüksek Lisans Tezi), Selçuk Üniversitesi Eğitim Bilimleri Enstitüsü, Konya. 